\title{
The Daily Image Information Needs and Seeking Behavior of Chinese Undergraduate Students
}

\section{Kun Huang and Diane Kelly}

\begin{abstract}
A survey was conducted at Beijing Normal University to explore subjects' motives for image seeking; the image types they need; how and where they seek images; and the difficulties they encounter. The survey also explored subjects' attitudes toward current image services and their perceptions of how university libraries might provide assistance. Based on the findings, this article summarizes the features of Chinese undergraduate students' daily image needs and their information behavior related to images. The findings reveal the need to improve the image services offered by academic libraries and strengthen undergraduates' information literacy with respect to image search and use.
\end{abstract}

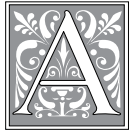

survey conducted by China Internet Network Information Center in 2009 reported that 44.7 percent of Google users in China use Google's image retrieval service, which is only second to use of Google's web page retrieval service. ${ }^{1}$ Image searching has clearly moved from a specialist task to an everyday information-seeking activity. ${ }^{2}$ In the field of education, it is recognized that images can enhance and stimulate the learning process and support innovative and effective teaching and learning. ${ }^{3}$ In today's world, faculty and students must have the ability to search, interpret, analyze, understand, use, and generate new visual information for communicating ideas and concepts. This is collectively referred to as visual literacy. ${ }^{4}$ It is fundamental to literacy in the digital age. ${ }^{5}$ Many university librarians have responded by providing access to licensed image databases; developing image datasets; and providing instruction about how to seek and evaluate images.

The use of professional image collections is lower than expected, however, and users still experience some difficulties in image seeking and use. Pisciotta, Dooris, Frost and Halm found that less than 10 percent of faculty and students reported ever having used specialized image collections provided by university libraries. ${ }^{6}$ In another study, Green found

Kun Huang is Associate Professor in the School of Management at Beijing Normal University, e-mail: huangkun@bnu.edu.cn; Diane Kelly is Associate Professor in the School of Information and Library Science at University of North Carolina at Chapel Hill, e-mail:dianek@email.unc.edu. This survey was supported by the Fundamental Research Funds for the Central Universities from China. The authors would like to thank Professor Barbara Moran for her valuable comments. We also thank Zhiyong Yang, Yiping Li, Sihe Zhang, and Hao Fu for collecting the data. Thanks to Xiaodi Tian, Yingmei Wu, Xiangquan Yin, and FeiFei Yin for providing information about Beijing Normal University Library. Thanks to Scott Miller for his editorial assistance. Thanks to the reviewers for valuable comments and constructive suggestions. (C2013 Kun Huang and Diane Kelly, Attribution-NonCommercial (http://creativecommons.org/licenses/by-nc/3.0/) CC BY-NC 
that most faculty reported never having used their college library's digital image collection, and many reported being unaware of such collections. ${ }^{7}$ Search engines seem to be the most popular way for people to obtain images and have been found to be a more common access method than using licensed and professional resources. ${ }^{8}$ To provide better image services for users within educational organizations and enhance the use of images in teaching and learning, this study was undertaken to determine the image needs of Chinese undergraduate students.

Differing from previous work, which focused more on image needs in specific academic domains (such as humanities, history, and arts), this study focused on the more general image needs of undergraduates from a range of disciplines. Moreover, it should be clarified that, while this study aims to understand undergraduates' ordinary image needs and seeking behavior, the scope of this work is not the same as that of everyday-life information seeking described by Savolainen. ${ }^{9}$ Similar to Yoon's, ${ }^{10}$ this study focused on both work-related and non-work-related needs and seeking behavior.

This work also differs from previous research in that most published studies about image information seeking have been conducted in Western societies with Western populations. Thus, this study provides a benchmark of Chinese students' image needs, which can be used for cross-cultural comparisons of image information-seeking behaviors. Results of this study reveal aspects of the image information-seeking process for which undergraduates need assistance; these results can thus be used to inform the design of interventions and instructional services.

\section{Literature Review}

The study of information behavior is a well-defined research area, ${ }^{11}$ but the research into image-information needs and seeking behavior has become active only in the last ten years. Some institutional research commissioned by universities and libraries has investigated image needs and use among students and faculty. For example, more than half of the faculty and students at The Pennsylvania State University have used digital or analog pictures for educational purposes. ${ }^{12}$ Faculty at Wesleyan University used digital images in 83 percent of the courses they taught. ${ }^{13}$ Seventy-two percent of the faculty at the University of California's Berkeley campus have used images or visual materials as resources. ${ }^{14}$ Although the digital images are used widely at universities, faculty and students don't use images provided by libraries very often. They obtain images from a variety of sources, such as personal collections, web search engines, public online databases, social networking sites, and commercial image databases. ${ }^{15}$ Obstacles faced by faculty and students include the inability to identify sources of images and organize distributed images; lack of knowledge of how to use images in different contexts; and lack of free, reliable access to digital images. ${ }^{16}$ Results showed that, to meet these users' needs, a good image service should provide effective, flexible search and new content discovery methods to reduce the burdens related to collecting and managing images. ${ }^{17}$ Moreover, effective image service systems serving education should provide powerful integration of digital technologies and resources to support teaching in diverse contexts. ${ }^{18}$

Some research focused more on specific image collections. This research examined how people described images when browsing the images or how they represented the queries. Enser and McGregor analyzed more than 2,700 user queries submitted to the Hulton Deutch CD Collection and established a twodimensional matrix of unique/nonunique, refined/nonrefined to describe the pattern of image queries. ${ }^{19}$ Later, Armitage and Enser analyzed user queries submitted to seven libraries that managed still 
and moving images, with the purpose of establishing a general categorization of image requests. ${ }^{20}$ Keister studied 239 queries submitted to the National Library of Medicine's Prints and Photographs and classified image requests into visual requests and topical requests with nonspecific visual requirements. ${ }^{21}$ Jörgensen \& Jörgensen selected 1,405 queries from a commercial image provider search log and found that descriptive and thematic queries and Boolean searching strategy were used frequently; they called for more support for query modification. ${ }^{22}$ Collins studied 127 patrons of the North Carolina State Archives and North Carolina Collection, finding that patrons used subject terms more often than any other kind of attribute. The image creator, physical form, genre, and visual terms were all used infrequently ${ }^{23}$ Matusiak recruited 12 users and examined their information-seeking behavior in the Milwaukee Neighborhoods collection. Results showed that multiple options for image discovery were helpful. ${ }^{24}$ Lee and Neal asked 138 library science graduate students to describe 16 photographs and found that objects in photographs and events taking place in the photographs were used most frequently. ${ }^{25}$

Some other research has focused on specific disciplines to study how people search for and use images. For example, in the field of Art History, users tended to use unique terms and seldom refine their queries. ${ }^{26}$ In the field of American History, most image content was represented in terms of people, thing, and event. Title, date and subject descriptors were used to describe images' subject content. ${ }^{27}$ In the field of Journalism, users frequently used specific entities and object types. ${ }^{28}$ Research has also shown that different relevance judgment criteria were used for different types of needs. For general and subjective needs, users depended more on personal feelings and textual information, while, for specific needs, users depended more on the objects contained in photos and were more likely to use topical relevance assessments. ${ }^{29}$ Furthermore, Frost et al. explored the difference of image-seeking behavior between experts and generalists. They discovered that art history specialists preferred direct search to browsing, while nonspecialists used browsing as their preferred mode. ${ }^{30}$ The findings were in line with Matusiak's that students with more searching experiences tended to select keyword searching, while community users who were older and less confident about searching skills preferred to select browsing. ${ }^{31}$ Similarly, Beaudoin conducted a comparison study across four fields including archaeologists, architects, art historians, and artists. This study indicated that profession had a marked but uneven impact on image

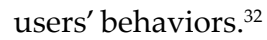

Other research explored more general image needs. Two common methods were used. One was to analyze the query logs of web search engines ${ }^{33}$ or queries posted to an online question and answer service. ${ }^{34}$ This research has identified popular search terms and attributes used in image searching and has shown that users' motivations for web image searching is often for entertainment purposes. ${ }^{35}$ These findings are consistent with the findings from a recent survey conducted by Yoon, which showed that most everyday imageinformation needs are conducted to satisfy one's curiosity, to gain knowledge, or to entertain. ${ }^{36}$ Similar findings could also be found in another survey conducted by Ruiz and Chin. ${ }^{37}$

The other method was to recruit subjects and ask them to write diaries to record activities related to image seeking or complete surveys. Cunningham and Masoodian asked 31 students of an HCI course to record their daily image needs and methods of search, finding that specific needs (such as a specific person, event, or activity) accounted for a majority of the daily image needs. ${ }^{38}$ Similarly, Chew et al. examined people's daily image use by asking nine people to record their Internet activities related to images and discovered that user motivations 
to seek images included learning and research, accessing images as secondary goals, recreating or connecting to remote experiences, and using images in communication. ${ }^{39}$ Apart from these, Ruiz and Chin ${ }^{40}$ and Yoon ${ }^{41}$ asked subjects to finish questionnaires to detect image needs and searching preferences.

Other researchers studied related impact factors on image-seeking behavior and examined how users evaluated the searching results. Choi recruited 29 students and asked them to perform searches using any information sources and channels they wanted. Results showed that task types could affect performance time, querying, navigation behavior, and the evaluations of the usefulness of search results. For example, users performing a search for an academic task goal tended to have long search sessions, modify queries frequently, and often find results less useful. ${ }^{42}$ Additionally, Vassilakaki et al. explored cross-language image-seeking behavior and discovered that translations were not considered helpful in this context due to their inconsistency in coverage and their tendency to lead to irrelevant results. ${ }^{43}$ Hung et al. ${ }^{44}$ and Hamid and Thom ${ }^{45}$ investigated relevance judgments criteria used in image retrieval. Based on Shatford's theory, ${ }^{46}$ three retrieval tasks, including Specific, General, and Abstract, were created. Results demonstrated that topicality, appeal of information, and composition were the common criteria across the search tasks.

In China, research about image seeking mainly discussed the principles for building general image resources and services at university libraries. ${ }^{47}$ Some research has discussed multimedia resource development and focused more on technical issues in establishing multimedia applications rather than focusing on users. ${ }^{48}$ Few studies have been done on image information-seeking behavior except $\mathrm{Pu}^{49}$ who analyzed a Chinese image search engine (VisionNEXT); and Cao, ${ }^{50}$ who conducted experiments to understand image-searching behavior, including the use of browsing and searching, entrance selection, and other behaviors. Other studies have mainly used the method of surveys to describe the general image needs of users. ${ }^{51}$ However, image needs have not been investigated at a more detailed level. The difficulties experienced by users and their expectations regarding image service have also not been explored.

In sum, the previous research has examined users' image needs and behaviors from different points of view and by using a variety of methods. With respect to university image services, some Western universities have laid great importance on image services but have been faced with the challenge of improving access and use. For most Chinese university libraries, their image services are under development, and the research has focused more on general multimedia information resources and technical issues. Therefore, further and deeper research on Chinese users is needed to understand and improve the usefulness and value of image collections, which is important for improving user satisfaction.

\section{Method}

This study focused on Chinese undergraduate students' general image needs (including daily life needs as well as school-related needs) and the obstacles faced when seeking and acquiring images in order to assist university libraries to develop their services. The following research questions were addressed:

- What motivates undergraduates to seek images and what are their image information seeking needs?

- How do undergraduates obtain images and what difficulties do they encounter?

- What are undergraduates' perceptions of the potential usefulness of university library image services?

The study was conducted in two phases. In Phase 1, face-to-face interviews were conducted with 20 participants to 


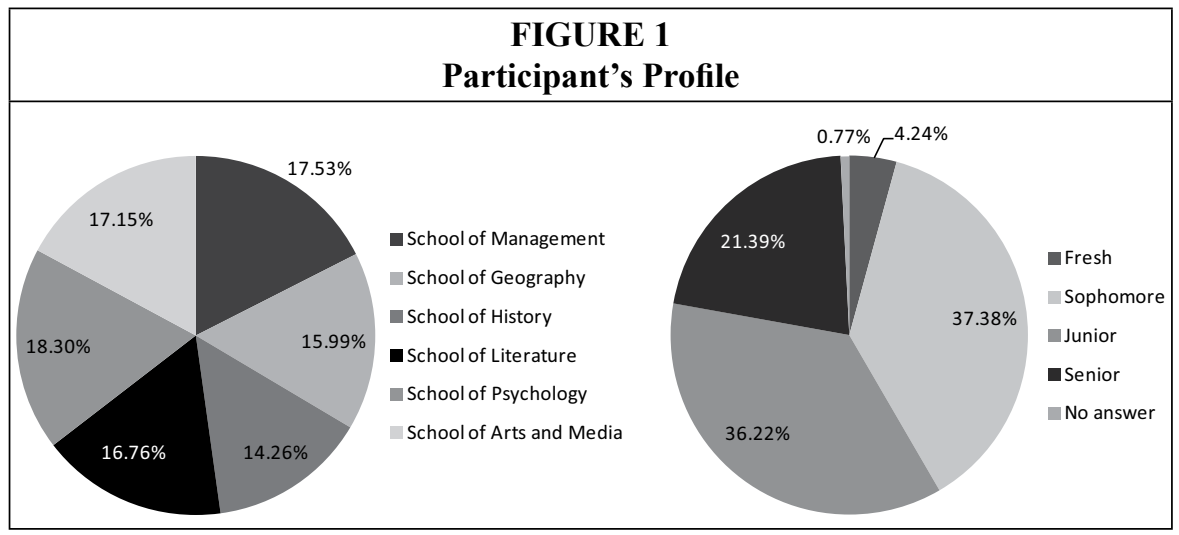

better understand the reasons students seek images, the sorts of images they frequently seek, and the way they find and obtain the images. Based on the findings and literature review, a structured questionnaire was developed for use in Phase 2, which addressed the research questions. Six hundred and one printed surveys were distributed to undergraduates in six schools (covering more than 13 majors) at Beijing Normal University (Figure 1) and 519 valid responses were collected, with a valid return rate of $86 \%$. The majority of the participants $(63 \%)$ were female. Thirtyfive percent were male, with another $2 \%$ unknown. Participants were primarily classified as sophomore, junior and senior students. Freshmen were underrepresented because only a small number were contacted during recruitment.

\section{Findings}

What Motivates Undergraduates to Seek Images and What are Their Image Information-Seeking Needs?

With respect to motivation, participants were first provided with three broad categories (Entertainment, Learning/ Studying, and Social Activities) and asked to select all that described their motivations to seek images. Entertainment was chosen by 78.42 percent of students, Learning/Studying by 75.72 percent, and Social Activities by 60.89 percent. Next, participants were provided with more specific options about their motivations, which were identified during Phase 1 interviews. The frequency of selection of these motivations is shown in figure 2.

The top choice was "To make PPT documents" (91.52\%). Mostundergraduate

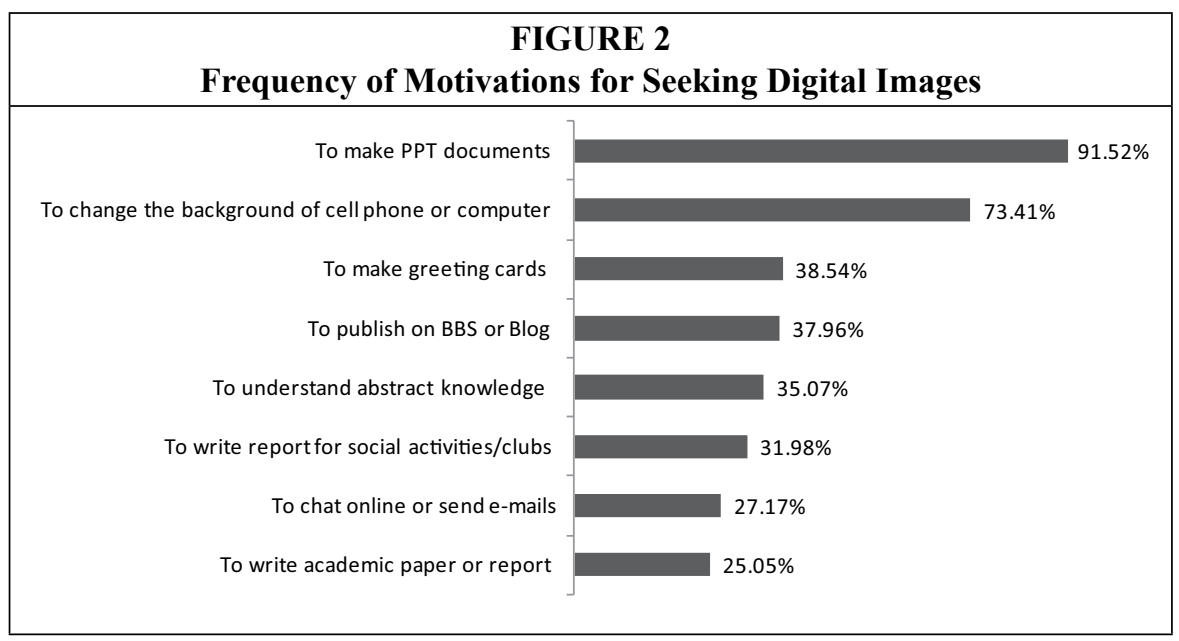




\begin{tabular}{|c|c|c|c|c|c|c|c|c|}
\hline & के & $\begin{array}{l}8 \\
\dot{0}\end{array}$ & $\stackrel{2}{\dddot{n}}$ & $\frac{0}{0}$ & $=$ & \begin{tabular}{l}
\multirow{2}{N}{} \\
0
\end{tabular} & $\begin{array}{l}\infty \\
0 \\
0\end{array}$ & $\stackrel{\infty}{\circ}$ \\
\hline & $\sum_{\substack{Z \\
\sum}}^{Z}$ & 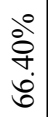 & 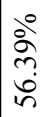 & 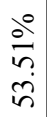 & $\left|\begin{array}{c}0 \\
0 \\
6 \\
0 \\
0 \\
n\end{array}\right|$ & $\mid \begin{array}{c}0 \\
\dot{0} \\
\dot{0} \\
\dot{0} \\
\dot{\gamma}\end{array}$ & $\begin{array}{l}\text { oे } \\
\text { oे } \\
\text { i }\end{array}$ & $\begin{array}{l}\text { oे } \\
\hat{\sigma} \\
\dot{\rho}\end{array}$ \\
\hline & 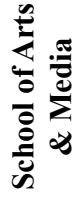 & $\begin{array}{l}\stackrel{0}{0} \\
\stackrel{+}{+} \\
\stackrel{0}{0}\end{array}$ & $\begin{array}{l}\stackrel{0}{0} \\
\hat{m} \\
\stackrel{m}{2}\end{array}$ & $\frac{0}{i n}$ & 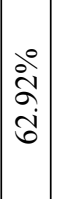 & $\begin{array}{c}\dot{0} \\
\dot{b} \\
\dot{j} \\
\dot{m}\end{array}$ & $\begin{array}{l}\stackrel{0}{0} \\
\vdots \\
0 \\
\dot{0}\end{array}$ & 官 \\
\hline & 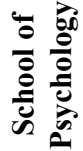 & $\begin{array}{l}\stackrel{\circ}{\Xi} \\
\stackrel{1}{\mathrm{i}}\end{array}$ & $\begin{array}{l}\stackrel{0}{0} \\
\hat{\jmath} \\
\infty \\
\infty\end{array}$ & $\begin{array}{l}\circ 0 \\
\infty \\
n \\
n \\
n\end{array}$ & $\left|\begin{array}{l}0 \\
\dot{+} \\
\infty \\
\dot{0} \\
i\end{array}\right|$ & 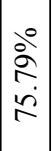 & 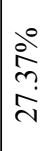 & $\begin{array}{l}\stackrel{0}{2} \\
\stackrel{2}{2} \\
\text { ñ }\end{array}$ \\
\hline$\overbrace{0}^{2}$ & 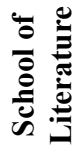 & 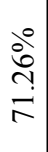 & 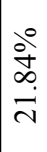 & $\begin{array}{l}\frac{0}{2} \\
\dot{n} \\
i n\end{array}$ & 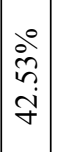 & $\mid \begin{array}{l}0 \\
\dot{0} \\
0 \\
0 \\
-1\end{array}$ & $\begin{array}{l}\stackrel{0}{0} \\
\hat{b} \\
\dot{0} \\
m\end{array}$ & $\begin{array}{c}\stackrel{0}{m} \\
\tilde{m} \\
m \\
m\end{array}$ \\
\hline 四 & 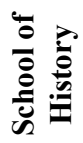 & 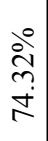 & $\begin{array}{l}\stackrel{0}{\circ} \\
\stackrel{n}{+}\end{array}$ & $\begin{array}{l}\stackrel{0}{ } \\
\grave{o} \\
\dot{1} \\
i n\end{array}$ & $\begin{array}{l}00 \\
\dot{0} \\
\dot{0} \\
\text { in }\end{array}$ & 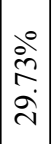 & 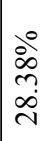 & $\begin{array}{l}\stackrel{0}{0} \\
\hat{\sigma} \\
\text { ஸे }\end{array}$ \\
\hline $\begin{array}{l}0 \\
0 \\
0 \\
0\end{array}$ & 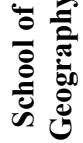 & $\begin{array}{l}\stackrel{0}{b} \\
\text { bे } \\
\text { ì }\end{array}$ & 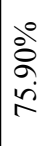 & $\begin{array}{l}\dot{b} \\
\stackrel{0}{0} \\
\stackrel{0}{0}\end{array}$ & $\frac{\stackrel{\circ}{\sigma}}{\stackrel{\infty}{\circ}}$ & $\begin{array}{c}0 \\
\dot{\infty} \\
\infty \\
i \\
i n\end{array}$ & $\frac{\partial^{\circ}}{\tilde{n}}$ & $\begin{array}{l}\stackrel{0}{\infty} \\
\stackrel{+}{+} \\
\stackrel{\sim}{\sim}\end{array}$ \\
\hline ల్రాల & 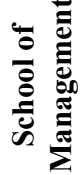 & $\begin{array}{l}\stackrel{0}{i} \\
\text { bे } \\
\dot{\vec{n}}\end{array}$ & $\stackrel{\stackrel{0}{े}}{\stackrel{m}{2}}$ & $\begin{array}{l}\dot{0} \\
\dot{0} \\
\stackrel{n}{n} \\
m\end{array}$ & 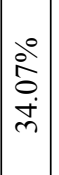 & $\begin{array}{l}\stackrel{0}{0} \\
\hat{n} \\
\hat{\sigma}\end{array}$ & $\mid \begin{array}{l}0 \\
0 \\
i n \\
\infty \\
N\end{array}$ & $\begin{array}{l}\stackrel{0}{0} \\
\dot{0} \\
\dot{\partial}\end{array}$ \\
\hline & & 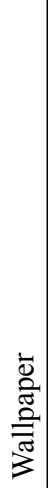 & 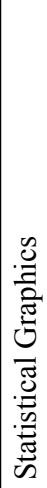 & 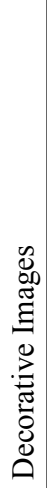 & 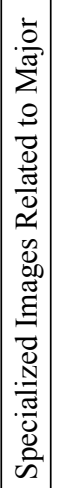 & 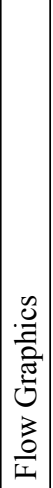 & 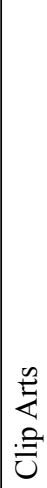 & 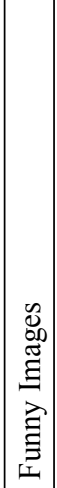 \\
\hline
\end{tabular}

courses require students to make a variety of individual and group presentations, and students also conduct research where they are required to present their results using PowerPoint. The second most popular choice was "To change the background of cell phone or computer" (73.41\%), which shows that many image needs are related to personal/environmental design tasks. Students' choices also demonstrated that images are often used for interpersonal communication. Students indicated that they used images to make greeting cards (38.54\%); enhance a BBS or blog $(37.96 \%)$; and when chatting online or sending e-mails (27.17\%). About 35 percent of students claimed that they seek images to understand abstract knowledge. Students also indicated they sought images to use in their writing, both for social activities/clubs (31.98\%) and for academic research $(25.05 \%)$.

Table 1 displays the types of images students seek and use. Results show that the top three image types students use are wallpaper $(66.40 \%)$, statistical graphics $(56.39 \%)$, and decorative images such as icons, buttons, lines (53.51\%). This is consistent with the findings in figure 2; wallpaper can not only be used as background graphics for cell phones and computers, but also to decorate PPT documents. For each school, over half of the students selected this option, which indicates that wallpaper is a common need of all students regardless of major.

Table 1 demonstrates that more students $(56.39 \%)$ seek statistical graphics than flow graphics (46.69\%). This reveals that images depicting numerical data and trends are more useful and necessary to students than those used to illustrate procedures and processes, but it also depends on different disciplines. Statistical graphics were selected by more students from the School of Psychology (86.32\%), School of Geography $(75.90 \%)$, and School of Management $(70.33 \%)$. These disciplines often depend on surveys, experiments, and field investigations, which produce statistical 
data and require many charts and tables. On the contrary, fewer students from the School of Literature (21.84\%) chose this image type. Similarly, flow graphics (graphics depicting processes that show the steps in the process as boxes of various kinds, and their order and relationships with arrows) were chosen by 75.59 percent students from School of Psychology, but only 16.09 percent of students from School of Literature. This result is unsurprising since students in Psychology often have to present the procedures of an experiment, or models of psychological processes, in course-related papers and presentations.

Regarding specialized images related to one's major, differences were found among six schools. Students from the following three schools have the greatest need for specialized subject-specific images: School of Arts \& Media (62.92\%), School of History (59.46\%) and School of Psychology (56.84\%). Fewer students from School of Geography (48.19\%), School of Literature $(42.53 \%)$, and School of Management $(34.07 \%)$ selected this option. The results show that undergraduate students from the first three schools depend more heavily on specialized images for their studies. For example, the School of Art \& Media encourages students to use images to design products and advertising, signs, and art photography. The School of History uses specialized images of famous or typical people, events, and places. The School of Psychology uses many specialized images for teaching containing dynamic optical illusions, color images, and facial expressions.

Illustration was identified as one of the most popular uses for images. Participants were asked to imagine if word processing software could automatically provide them with images to accompany the text, what types of images they would prefer. Three choices were provided: images representing the objective meaning of the text, images representing the subjective meaning of the text (for instance, attitudes and emotions) and images for decorating the document. The result indicated the majority of the students $(73.99 \%)$ desired images representing the objective meaning of the text. Interestingly, over two thirds (68.79\%) of students desired images representing subjective meaning. Only 26.40 percent chose decorative images. Four students filled the blank for "Other" and stated that the images should be individual and reflect emotions of authors. These results reveal that when images are used as sources of objects, the subject and effect of images are both important in image use, which suggests the importance of image seeking by affective in addition to content.

\section{How Do Undergraduates Obtain Images and What Difficulties Do They Encounter?} Figure 3 summarizes the sources used by students to obtain or locate desired images and the percentage of students who selected the different sources.

On average, students selected 3.20 $(\mathrm{SD}=1.73)$ sources, which indicates that students use multiple sources to seek images. In terms of general sources, the most popular was search engines $(93.83 \%)$. A total of 339 students identified the search engine they used regularly. About 88 percent of the students identified Baidu and 48.97 percent identified Google (some students identified both of these). About 30 percent of the students reported using general information portals, such as Sina and Sohu, which are better suited for browsing and nonpurposeful image seeking. Eight students filled in the blank for "Other." They were all from the School of Arts and Media. Four of them said they would draw images, and one said he used his own image collection. The other three answers were already included in the choices given (such as searching the web, taking pictures).

In terms of sources provided by professionals, fewer than 15 percent chose these options. Only 10.98 percent reported getting images from libraries. Since most of students' self-reported image needs were related to presentation documents or 


\begin{tabular}{|c|c|c|}
\hline $\begin{array}{r}\text { FIGUR } \\
\text { How Students Ac }\end{array}$ & $\begin{array}{l}3 \\
\text { uire Images }\end{array}$ & \\
\hline Search engine & & 93.83\% \\
\hline General information portal (Sina, Sohu) & $30.06 \%$ & \\
\hline Specific image databases or compact disk & $14.64 \%$ & \\
\hline Library's website & $10.98 \%$ & \\
\hline Internal database & $10.21 \%$ & \\
\hline Web community or forum & 33.72 & \\
\hline Take pictures & & $63.01 \%$ \\
\hline Others (such as teachers, classmates or friends) & $25.24 \%$ & \\
\hline Copyscreen & $23.89 \%$ & General Source \\
\hline Scan & $12.52 \%$ & Professional Source \\
\hline & & $\begin{array}{l}\text { User-generated Source } \\
\text { Personal Source }\end{array}$ \\
\hline
\end{tabular}

decoration, this is unsurprising. Furthermore, Beijing Normal University Library only recently made available specialized image datasets so students might not be aware of the library resources.

In terms of user-generated sources, which refer to web communities and forums, it's not surprising that only 33.72 percent of students have collected images this way, even though social media have become so popular. This kind of source has a higher entry barrier for users, since different web communities have different user groups and image types. Without knowledge of these sources, it is much harder to obtain images from them, and they are more difficult to find through regular search.

In terms of personal sources, the most popular was personal photography

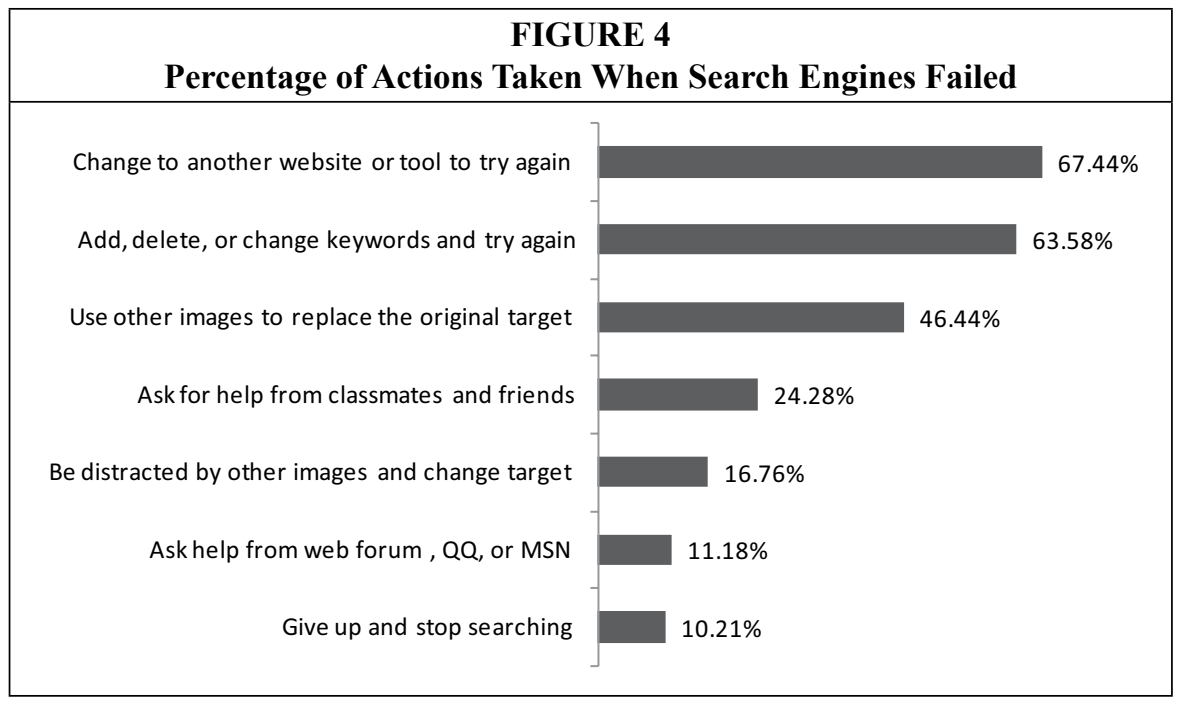


(63.01\%). Digital cameras have become a basic function of cell phones, providing students more opportunities to take pictures. Students also frequently copy computer screens and create images (23.89\%). Only 12.52 percent would scan physical materials to get images, which is unsurprising since this requires additional effort and resources. Students were also asked whether their instructors have provided them with images. Over 90 percent reported that instructors have provided related images.

Most students indicated that they search for images using search engines by entering keyword queries. Previous research has shown that this strategy is often unsuccessful, especially when image needs are ambiguous. Figure 4 displays the students' responses when their keyword searches were unsuccessful.

Figure 4 indicates most students keep the original image need and try other search tools $(67.44 \%)$ or refine their queries $(63.58 \%)$. About 46 percent use other images to replace the original target, and 16.76 percent allow themselves to become distracted by other images. Nearly 25 percent indicated they would ask for help from classmates and friends, which is higher than the percentage asking for help in web forums and by using instant message software
(11.18\%). Another 10.21 percent reported they would stop their searches if their initial queries failed.

Students were asked which improvements would be helpful in an image search system. The frequency of desired improvements is shown in figure 5 . Over 60 percent believed systems should provide feeling, impression, or sensebased image search functions. Nearly 50 percent advocated an advanced retrieval function for ambiguous queries and a natural language-based retrieval function. Fewer preferred to query by setting visual parameters $(45.47 \%)$, drawing $(37.38 \%)$, or providing image example $(36.22 \%)$.

Differences in desired improvements were found among students from the different schools. Results show that students from the School of Geography preferred to search images by drawing a draft $(50.60 \%)$ or by giving an example $(45.78 \%)$. On the contrary, only 22.99 percent of the students from the School of Literature desired to use drawing as a method to enter a query, and only 27.03 percent of students from the School of History desired to query based on image example.

To better understand the difficulties faced by students when searching for images, 10 obstacles were presented (see figure 6). Students experienced two major

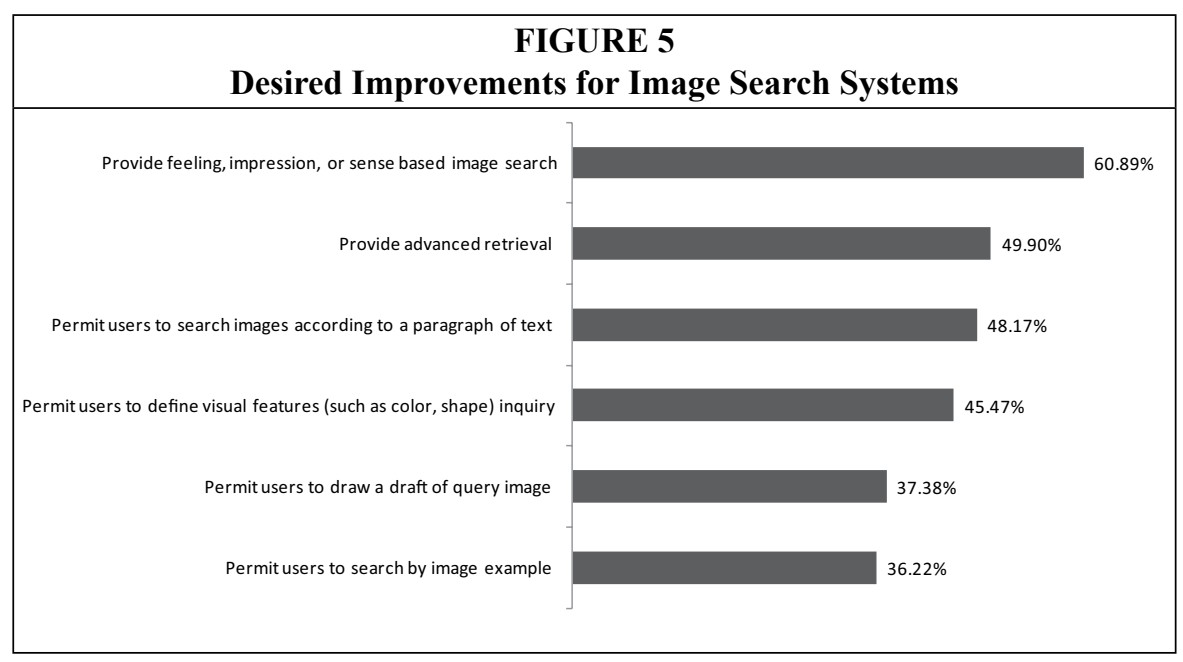




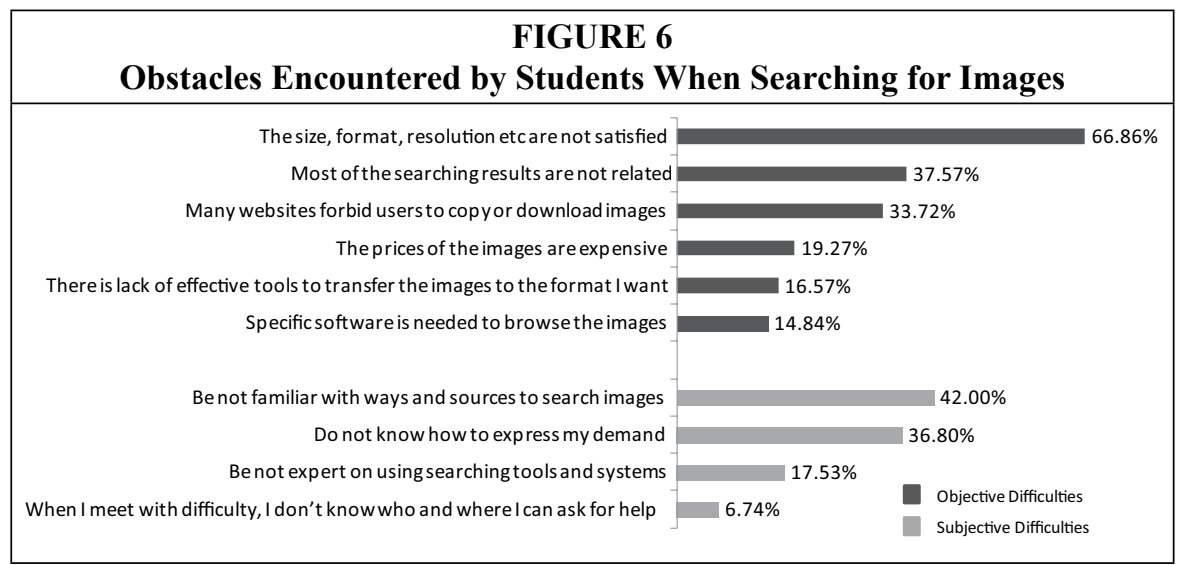

sources of difficulties. One was caused by a lack of system functions (referred to as objective difficulties) and the other was caused by students' low information literacy with respect to image searching (referred to as subjective difficulties).

In terms of objective difficulties, 66.86 percent report that the size, format, and resolution of images are often unsatisfactory, while 37.57 percent reported that "most of the searching results are not related." This is an interesting finding, as it suggests that other types of relevance (besides topical) are important when searching for images. Students also indicated that they often could not use the image because it was not permitted $(33.72 \%)$, or because they would be charged a fee that was too expensive (19.27\%). Few students indicated that they experienced difficulties transferring the image or lacked special software to view the images (16.57\% and $14.84 \%$ respectively).

In terms of subjective difficulties, the top one was a lack of knowledge about how and where to search for images $(42 \%)$. The second most frequently selected obstacle was difficulty in expressing their needs $(36.8 \%)$. Fewer reported difficulties related to lack of expertise on using tools and systems to search (17.53\%) and confusion about how to seek help (6.74\%). Most major search engines allow users to directly query images, so it is no surprise that most students did not indicate difficulties identifying search tools.

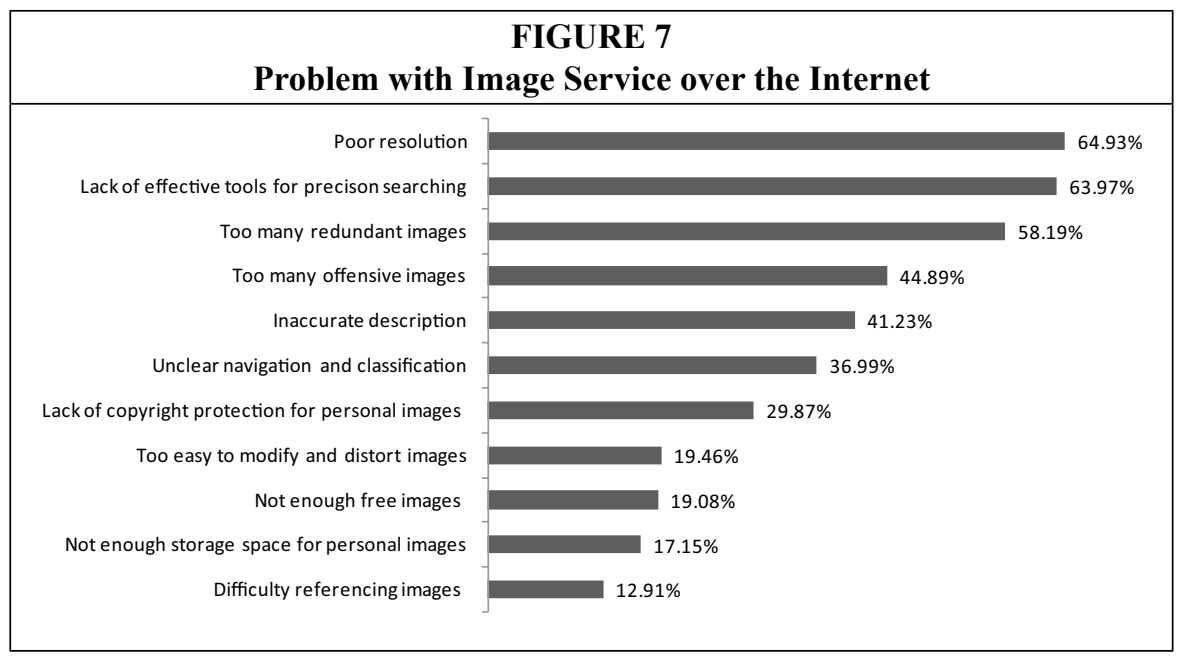


However, most of these engines only present users with the traditional search box and do not offer support for query formulation and reformulation. On the whole, students from different disciplines faced similar obstacles.

Participants were asked what was problematic about current image services (see figure 7). The top problem selected was the poor resolution (64.93\%) of the images found, which was identified slightly more often than lack of effective searching tools $(63.97 \%)$. Nearly 60 percent of students reported redundancy in the images provided by different websites, and 44.89 percent pointed out that there were too many offensive images, which often made searching more difficult. In addition, 41.23 percent indicated that image descriptions are often inaccurate. Only 36.99 percent expressed dissatisfaction with structures that facilitate browsing (navigation and classification), which is lower than that reported for direct search tools.

\section{What are Undergraduates' Perceptions of the Potential Usefulness of University} Library Image Services?

When participants were asked how useful they believed images would be to their studies, 79.57 percent agreed they would be useful: 36.22 percent said strongly useful, while 43.35 percent said weakly useful. Over 80 percent of the students from the Schools of Arts and Media, Geography, History, and Psychology responded positively to this question, which was much higher than the Schools of Literature and Management. Students were also asked about their satisfaction with current Internet-based image services. Only 3.28 percent reported that they are very satisfied, and 28.52 percent reported they are weakly satisfied. Most students took neutral attitudes $(47.40 \%)$.

Finally, students were asked whether they believed the university library should establish or strengthen its image services and to provide a reason for their response. About four-fifths of the students replied positively to this ques- tion. Their reasons included the idea that, although there are many images available over the Internet, the huge number creates a burden to search and selection. They believed that library-managed systems could reduce their labor in gathering or managing images and librarians could help them integrate images from different sources, especially providing high-quality and copyright-cleared images.

The remaining one-fifth of the students did not find it necessary for the library to establish or strengthen image services. They thought that collecting images from the Internet was sufficient, and that the major responsibility of the university library was to manage books and journals, not images. Some of them were suspicious about the feasibility of establishing a good image service and were concerned that the technical and copyright issues would bring great challenges; and, even if the library tried to overcome the difficulties, the results may not be satisfying.

\section{Discussion and Implications \\ Daily Image Needs}

The results showed that the majority of undergraduates' image needs were associated with entertainment, which was consistent with the findings from studies using both questionnaires ${ }^{52}$ and search logs. ${ }^{53}$ This may help explain why some licensed resources at the university library were underused, for most libraries focus on buying specialized image datasets. Another high-frequency need was related to the students' class assignments. Students were more likely to use images for presentations rather than for papers, which is consistent with Yoon's findings. ${ }^{54}$ In our study, this may be attributed to the fact that most teachers already provided related images. This reinforces the findings that most faculty believe images make abstract information more accessible to audiences and put great effort into preparing images for courses..$^{55}$

The results indicated that students frequently used wallpaper, statistical graphics, and decorative images. Based 
on the work of Fidel, ${ }^{56}$ who used a continuum with two poles (data pole and object pole) to describe image use, the results indicated that images were needed as sources of objects more than as sources of data in undergraduates' daily use. These results are similar with McCayPeet and Toms' findings that images are used more as illustration rather than information for general use. ${ }^{57}$ Conniss et al..$^{58}$ identified seven types of image uses (aesthetic value, emotive/persuasive purposes, illustration, generation of ideas, information dissemination, information processing, and learning); the findings from figure 1 and table 1 show that students often use images for illustration, aesthetic, and information dissemination more than learning. Similarly, Chung and Yoon noted that illustration was the most prominent use for images, with idea generation following; images were used for learning less than for aesthetic purposes, ${ }^{59}$ which is also aligned with our findings.

These findings suggest a reasonable question about which types of needs libraries should support. Traditionally, libraries have provided access to fee-based services that contain specialized images such as ARTstor. However, libraries can potentially address many image needs by providing better access to free image sources. One of the most prevalent image needs was related to decorative images. While providing students with these types of images might be viewed as slightly nontraditional since this is not for academic purposes, these types of needs are likely to grow in the future as multimedia presentations become a normal part of academic coursework. Identifying and assembling useful places where students can access these types of images for free and without copyright concerns would be potentially useful.

\section{Image Source and Image Search}

The majority of students used search engines or took pictures to obtain images far more than they used image databases licensed by university libraries. Few used scanning, which was even less common than copying screens. That was not merely due to the lack of convenience for scanning, but also related to the reason that most of the images students used were already digitized. With respect to the use of social media sites, although web media has developed rapidly in recent years, only a small portion of students indicated that they used images from Web 2.0 communities and often, the purpose of visiting these sites was not for image seeking but for sharing images with friends to support social relationships. Similar findings were described by Angus and Thelwall. ${ }^{60}$

With respect to image-searching behavior, the survey focused more on behavior in the face of search failures. Results showed that students would often adjust their queries or allow themselves to become distracted by other images and/or change their search targets. This suggests that students' search tasks are often ambiguous and/or ill-defined and that image searching is dynamic. It makes sense that searchers would gain new knowledge of their retrieval task and the image collection through the search process and the image sets retrieved. This reflects that image search behavior is very much aligned with Bates ${ }^{\prime 61}$ berry picking model and well-suited to Campbell's $s^{62}$ ostensive relevance feedback model, which models dynamic relevance and evolving information needs. These results suggest that image search systems should support more fluid and dynamic interactions. However in practice, designers need to keep a balance between providing multiple points of access and avoiding cognitive overload. ${ }^{63}$ Therefore, it is essential to understand image users deeper. Finally, students' approaches for overcoming failed searches were limited, which indicates the importance of user instruction in this domain.

The findings of the survey also suggest the need for affective image retrieval and advanced retrieval. The survey results indicated that students desired to 
search images based on affective features rather than content-based features. This reinforced the findings of Eakins et al.'s study ${ }^{64}$ that users were more interested in concept-based than content-based retrieval. Previous research has found that novices are more likely to use emotive or interpretive content to describe images. ${ }^{65}$ Previous research has related iconology to people's personal interpretations of image content. For example, Panofsky analyzed Renaissance art images and found that users' interpretation were related to three levels of meaning, pre-iconography, iconography, and iconology. ${ }^{66}$ Later, Shatford extended Panofsky's work and classified the subjects of images as "Generic Of," "Specific Of." and "About." "About" referred to moods, emotions, and abstractions; ${ }^{67}$ this is similar to "emotional level" 68 and "soft indexing." ${ }^{\prime 69}$ Affective was regarded helpful to improve the efficiency of image retrieval ${ }^{70}$ and has been studied for quite some time in image research, ${ }^{71}$ but few (if any) commercial services allow for indexing or searching based on affective properties.

\section{Obstacles and Attitudes}

One of the biggest obstacles faced by students is their limited knowledge of available image services and of how to express their needs, which supports the efforts of instructional librarians who have created courses focused on visual information literacy. In accordance with Yoon's survey, ${ }^{72}$ students have limited knowledge about available image sources and do not know how to express their needs in an effective way, which may be due to low information literacy with respect to images and other multimedia. When searching for text documents, the relationship between query terms and index terms is somewhat straightforward; but images are indexed in a variety of ways, and issues of aboutness are compounded by the fact that images are visual representations, not textual representations. Different from web information retrieval, the size, format, and resolution of images are also important selection criteria; these features were used more by students than the preciseness of the match between query and image to determine relevance. Sharpness was also identified as an important criterion, especially during the selection stage. ${ }^{73}$

The importance of images in learning was acknowledged by most students, even though it was not the most popular reason motivating their image seeking. Most students felt positive about the librarian assistance with image information seeking. Although a search engine was the dominant way for students to locate images, most students believed that the images selected and organized by professional librarians would be more beneficial.

To enhance image services, many measures can be taken. One example would be to develop path finders for free images, since so many are available over the Internet. ${ }^{74} \mathrm{~A}$ file sharing system could also help students access more images. ${ }^{75}$ Users could also benefit from more instruction to help them improve visual information literacy, especially if more attention is placed on the informationseeking and use components. ${ }^{76}$ University libraries, including those in China, have traditionally provided information literacy instruction with regard to traditional media types such as newspaper, journal articles, and books, but instruction on specialized media types such as images and other multimedia are less common, except perhaps in specialized courses for specific types of students. In today's world, it is increasingly important for all students to develop visual literacy skills.

\section{Conclusion}

This survey focused on Chinese undergraduate students, examining their image needs, sources, and searching strategies, and obstacles and attitudes toward image services. The results have implications for both university libraries and image service providers. They can not only be used to improve current 
image services, but also to develop new services. Results show that providing navigational aids can potentially help improve students' access to both free and licensed images. More diverse retrieval functions such as affective retrieval would also be helpful. Furthermore, university libraries should consider providing additional information literacy courses in the areas of image information seeking and visual literacy.

This research only investigated undergraduate students at one Chinese university, Beijing Normal University. Although the findings provide useful insights, further research is needed. With respect to cultural differences, Yoon ${ }^{77}$ has discovered that relevance criteria and searching strategy are the elements of search that are most influenced by culture. While our study was not a comparative analysis across cultures, the findings did not differ substantially from similar published studies with
Western populations. However, one key difference was that Chinese students had a great need for wallpaper, statistical graphs, and decorative images. There may be additional differences that we did not detect.

This study is one of the first to document the image information-seeking needs of Chinese undergraduate students. While many studies have been done using Western populations, few have examined this specific population. Given the increase in the number of international students, and Chinese students in particular, attending universities in Western countries, it is important for librarians to be aware that students from different countries might have different information- seeking needs and exhibit different information search behaviors than their Western counterparts. This research might help libraries better understand the image information-seeking needs of this specific population.

\section{Appendix}

\section{A Survey of Image Information Needs among Undergraduate Students at Beijing Normal University \\ (original form in Mandarin; translated into English for publication)}

This survey aims to understand why you seek images, how you find images, the difficulties you encounter, your attitudes toward current image services and your perceptions of how university libraries might provide assistance. This survey is anonymous and the data will only be used for academic research. The survey takes 10-15 minutes to complete.

School:

Major:

Gender: O Male O Female Grade: O Freshman $\bigcirc$ Sophomore $\bigcirc$ Junior $\bigcirc$ Senior

Note: Please respond to each of the items below. The symbol $\bigcirc$ means that you can choose only one response. The symbol $\square$ means that you can choose multiple responses.

\section{Part I: Image Needs}

1. Indicate the motivation of your image seeking over the Internet.

$\square$ Entertainment $\square$ Learning or studying $\square$ Social activities $\square$ Other 
2. For which specific reasons do you search images?

$\square$ To understand abstract knowledge $\quad \square$ To write academic paper or report

$\square$ To make PPT documents $\quad \square$ To publish on BBS or Blog

$\square$ To chat online or send e-mail

$\square$ To change the background of cell phone or computer

$\square$ To make greeting cards $\quad \square$ To write report for social activities/club

$\square$ Other

3. Which kinds of images do you use in your major courses?

$\square$ Statistical graphics $\square$ Flow graphics $\square$ Clip arts $\quad \square$ Wallpaper

$\square$ Funny images $\quad \square$ Decorative images (such as icons, buttons, and lines)

$\square$ Specialized images related to major $\square$ Other

4. When you're writing, if the editing software was able to automatically provide you with a picture to accompany your text, what kind of images would you want?

$\square$ Images representing the objective meaning of the text

$\square$ Images representing the subjective meaning of the text (such as attitudes and emotions)

$\square$ Images for decorating the text

$\square$ Other

\section{Part II: Image Seeking (Image Sources and Image Searching)}

5. How do you acquire images?

$\square$ Search engine $\square$ Web community or forum $\square$ Specific image databases or compact disk

$\square$ Library's website $\square$ Take pictures $\square$ Scan

$\square$ Ask for help from teachers, classmates, or friends $\square$ Copy screen

$\square$ Internal database $\square$ General information portal (such as Sina, Sohu)

$\square$ Other

6. Do your instructors provide images as part of your courses?

O Yes O No

7. Please list the search engine you always use

When the search engine fails to find what you want, what will you do?

$\square$ Add, delete, or change keywords and try again

$\square$ Change to another website or tool to try again

$\square$ Ask help from classmates and friends

$\square$ Use other images to replace the original target

$\square$ Give up and stop searching

Ask help from web forum, QQ, or MSN

$\square$ Be distracted by other images and change target

Other

8. Which of the following functions would you like an image service to provide?

$\square$ Permit users to draw a draft of query image

$\square$ Provide feeling, impression, or sense based image search

$\square$ Permit users to define color, shape, and layout of elements of the images query

$\square$ Permit users to search by image example

$\square$ Permit users to search images according to a paragraph of text

$\square$ Provide advanced retrieval

$\square$ Other 


\section{Part III: Difficulties and Problems}

9. Which difficulties have you encountered when searching for images?

$\square$ Unfamiliar with ways and sources to search images

$\square$ Lack of expertise on using searching tools and systems

$\square$ Do not know how to express my demand

$\square$ Most of the searching results are not related

$\square$ Many websites forbid users to copy or download images

$\square$ The size, format, resolution, and such are not satisfied

$\square$ Specific software is needed to browse the images

$\square$ The prices of the images are expensive

$\square$ There is lack of effective tools to transfer the images to the format I want

$\square$ Lack of knowledge about how to seek help

$\square$ Other

10. What is problematic about current image services?

$\square$ Lack of effective tools for precision searching

$\square$ Too many redundant images

$\square$ Poor resolution

$\square$ Not enough free images

Not enough storage space for personal images

$\square$ Difficulty referencing images

$\square$ Lack of copyright protection for personal

$\square$ Too many offensive images

$\square$ Inaccurate descriptions

$\square$ Unclear navigation and classification

$\square$ Too easy to modify and distort images

$\square$ Other

\section{Part IV: Attitudes}

11. How useful are images to your studies?

$\bigcirc$ very useful $\bigcirc$ weakly useful $\bigcirc$ somewhat useful $\bigcirc$ not very useful $O$ not at all useful

12. To what extent do you agree with the statement that current Internet-based image services do an adequate job of meeting users' needs?

$\bigcirc$ strongly agree $\mathrm{O}$ agree $\mathrm{O}$ neither agree or disagree $\mathrm{O}$ disagree $\mathrm{O}$ strongly disagree

13. Do you think it is necessary for library to establish or strengthen its image services? O Yes O No

If yes, the reason is:

If no, the reason is: 


\section{Notes}

1. China Internet Network Information Center, “Report on Chinese Search Engine Users' Behavior in 2009" (Sept. 21, 2009), available online at research.cnnic.cn/html/1253600840d1370. html [accessed 6 May 2010].

2. Sally Jo Cunningham and Masood Masoodian, "Looking for A Picture: An Analysis of Everyday Image Information Searching," in JCDL 06: Proceedings of the 6th ACMIEEECS Joint Conference on Digital Libraries, Chapel Hill, NC, June 11-15, 2006: 198-199.

3. Elaine Mowat, "Teaching and Learning with Images," VINE 32, no. 3 (2002): 5-13.

4. Suzanne Stokes, "Visual Literacy in Teaching and Learning: A Literature Perspective," Electronic Journal of the Integration for Technology in Education 1, no. 1 (2002): 10-19.

5. Peter Felten, "Visual Literacy," Change: The Magazine of Higher Learning 40, no. 6 (2008): 60; Kathleen Tyner, Literacy in a Digital World: Teaching and Learning in an Age of Information (Mahwah: Lawrence Erlbaum Associates, 1998).

6. Henry A. Pisciotta, Michael J. Dooris, James Frost, and Michael Halm, "Penn State's Visual Image User Study," portal: Libraries and the Academy 5, no. 1 (2005): 37.

7. David Green, "Using Digital Images in Teaching and Learning: Perspectives from Liberal Arts Institutions" (Oct. 2006), available online at www.academiccommons.org/imagereport [accessed 6 May 2010].

8. Xuefang Zhu, Shunbo Yuan, and Qiang Xu, "A Survey of the Present Status of the Application of Digital Images in China," Journal of Library Science in China 34, no. 1 (2008): 56-59.

9. Reijo Savolainen, "Everyday Life Information Seeking: Approaching Information Seeking in the Context of 'Way of Life,'” Library \& Information Science Research 17, no. 3 (1995): 259-94.

10. JungWon Yoon, "Searching Images in Daily Life," Library \& Information Science Research 33, no. 4 (2011): 269-75.

11. T.D. Wilson, "Human Information Behavior," Information Science 3, no. 2 (2000): 49-55.

12. Pisciotta, Dooris, Frost, and Halm, "Penn State's Visual Image User Study," 36.

13. Green, "Using Digital Images in Teaching and Learning: Perspectives from Liberal Arts Institutions," 10.

14. Diane Harley et al., "The Use of Digital Resources in Humanities and Social Science Undergraduate Education" (Oct. 2004): 36, available online at cshe.berkeley.edu/research/digitalresourcestudy/documents/digital_resources_y1_report.pdf [accessed 10 March 2010].

15. Green, "Using Digital Images in Teaching and Learning," 11; Boon Chew, Jennifer A. Rode, and Abigail Sellen, "Understanding the Everyday Use of Images on the Web," Proceedings of the 6th Nordic Conference on Human-Computer Interaction: Extending Boundaries (2010): 104.

16. Jill Evans, "The FILTER Project: Encouraging the Use of Digital Images for Learning, Teaching and Research," VINE 32, no. 3 (2002): 38; Harley et al., "The Use of Digital Resources in Humanities and Social Science Undergraduate Education," 41.

17. Pisciotta, Dooris, Frost, and Halm, "Penn State's Visual Image User Study," 47.

18. Tufts University Information Technology, "Teaching and Learning Art History with Digital Images" (2006), available online at uit.tufts.edu/?pid=569\&c=405 [accessed 15 March 2010].

19. Peter G.B. Enser, "Query Analysis in a Visual Information Retrieval Context," Journal of Document and Text Management 1, no. 1 (1993): 25-52; Peter G.B. Enser and C. McGregor, "Analysis of Visual Information Retrieval Queries," British Library Research and Development Report, 6104 (1992).

20. Linda H. Armitage and Peter G.B. Enser, "Analysis of User Need in Image Archives," Journal of Information Science 23, no. 4 (1997): 287-99.

21. Lucinda H. Keister, "User Types and Queries: Impact on Image Access Systems," in Challenges in Indexing Electronic Text and Images, eds. R. Fidel, P. Smith, T. Hahn, and E. Rasmussen (1994): 7-22.

22. Corinne Jörgensen and Peter Jörgensen, "Image Querying by Image Professionals," Journal of the American Society for Information Science and Technology 56, no. 12 (2005): 1346-59.

23. Karen Collins, "Providing Subject Access to Images: A Study of User Queries," American Archivist 61, no. 1 (1998): 36-55.

24. Krystyna K. Matusiak, "Information Seeking Behavior in Digital Collections: A Cognitive Approach," Journal of Academic Librarianship 32, no. 5 (2006): 479-88.

25. Hyuk-Jin Lee and Diane Neal, "A New Model for Semantic Photograph Description Combining Basic Levels and User-assigned Descriptors," Journal of Information Science 36, no. 5 (2010): $547-65$.

26. Hsin-liang Chen, "An Analysis of Image Queries in the Field of Art History," Journal of the American Society for Information Science and Technology 52, no. 3 (2001): 272.

27. Youngok Choi and Edie M. Rasmussen, "Searching for Images: The Analysis of Users' 
Queries for Image Retrieval in American History," Journal of the American Society for Information Science and Technology 54, no. 6 (2003): 498.

28. Stina Westman and Pirkko Oittinen, "Image Retrieval by End-Users and Intermediaries in a Journalistic Work Context," in Proceedings of the 1st International Conference on Information Interaction in Context, IIiX 2006, Copenhagen, Denmark, October 18-20, 2006: 109.

29. Tsai-Youn Hung, Chuck Zoeller, and Santiago Lyon, "Relevance Judgments for Image Retrieval in the Field of Journalism: A Pilot Study," Digital Libraries: Implementing Strategies and Sharing Experiences: 8th International Conference on Asian Digital Libraries, Lecture Notes in Computer Science 3815, (2005): 79.

30. C. Olivia Frost et al., "Browse and Search Patterns in a Digital Image Database," Information Retrieval 1, no. 4 (2000): 287-313.

31. Matusiak, "Information Seeking Behavior in Digital Collections," 486.

32. Joan Beaudoin, "A Preliminary Investigation of Image Indexing: The Influence of Domain Knowledge, Indexer Experience and Image Characteristics," 19th Annual ASIS SIG/CR Classification Research Workshop (2008), available online at digital.lib.washington.edu/ojs/index.php/acro/ issue/view/869 [accessed 3 June 2011].

33. Abby Goodrum and Amanda Spink, "Image Searching on the Excite Web Search Engine," Information Processing \& Management 37, no. 2 (2001): 295-312; Bernard J. Jansen, "Searching for Digital Images on the Web," Journal of Documentation 64, no. 1 (2008): 81-101.

34. EunKyung Chung and JungWon Yoon, "Image Needs in the Context of Image Use: An Exploratory Study," Journal of Information Science 37, no. 2 (2011): 163-77; JungWon Yoon and EunKyung Chung, "Understanding Image Needs in Daily Life by Analyzing Questions in a Social Q \& A Site," Journal of the American Society for Information Science and Technology 62, no. 11 (2011): 2201-13.

35. Hsiao-Tieh Pu, "An Analysis of Web Image Queries for Search," Proceedings of the American Society for Information Science and Technology 40, no. 1 (2003): 340-48.

36. Yoon, "Searching Images in Daily Life," 271.

37. Miguel E. Ruiz and Pok Chin, “Users' Image Seeking Behavior in a Multilingual Tag Environment," Lecture Notes in Computer Science 6242 (2010): 37-44.

38. Cunningham and Masoodian, "Looking for A Picture," 198-99.

39. Chew, Rode, and Sellen, "Understanding the Everyday Use of Images on the Web," 102-11.

40. Ruiz and Chin, "Users' Image Seeking Behavior in a Multilingual Tag Environment," 37-44.

41. Yoon, "Searching Images in Daily Life," 269-75.

42. Youngok Choi, "Effects of Contextual Factors on Image Searching," Journal of the American Society for Information Science 61, no. 10 (2010): 2019; Youngok Choi, "Investigating Variation in Querying Behavior for Image Searches on the Web," Proceedings of the American Society for Information Science and Technology 47, no. 1 (2010): 1-10.

43. Evgenia Vassilakaki, Frances Johnson, Richard J. Hartley, and David Randall, "A Study of Users' Image Seeking Behaviour in FlickLing," Proceedings of the 9th Cross-Language Evaluation Forum Conference on Evaluating Systems for Multilingual and Multimodal Information Access, Lecture Notes in Computer Science 5706 (2009): 251-59.

44. Hung, Zoeller, and Lyon, "Relevance Judgments for Image Retrieval in the Field of Journalism," 72-80.

45. Rahayu A. Hamid and James A. Thom, "Criteria That Have an Effect on Users While Making Image Relevance Judgments," Proceedings of the Fifteenth Australasian Document Computing Symposium, Melbourne, Australia (Dec. 10, 2010): 76-83.

46. Sara Shatford, "Analyzing the Subject of a Picture: A Theoretical Approach," Cataloging $\mathcal{E}$ Classification Quarterly 6, no. 3 (1986): 39-62.

47. Dongmin Qiao and Liping Yu, "A Survey of Users' Information Needs in Colleges under New Information Surrounding," Library and Information, no. 4 (2010): 91-93, 99.

48. Ping Ren, Jia Lin, and Chenggang Zhao, "Establishment of Library Multimedia Resources System for Management and Service-Taking Tsinghua University Library as an Example," New Technology of Library and Information Service, 2 no. 6 (2007): 79-82.

49. Pu, "An Analysis of Web Image Queries for Search," 340-48.

50. Mei Cao, "Research on Key Behaviors of Image Retrieval on Internet," New Technology of Library and Information Science, no. 12 (2010): 40-45; Mei Cao and Yufeng Min, "Research on Image Retrieval Behavior of Entrance Selecting and Jumping on Internet," Library and Information Science, no. 4 (2011): 38-43; Mei Cao, "Users' Information Behavior and Psychology in Image Retrieval on the Internet," Journal of Library Science in China, no. 9 (2011): 53-60.

51. Zhu, Yuan, and Xu, "A Survey of the Present Status of the Application of Digital Images in China," 56-59; Shunbo Yuan and Juanxian Wu, "Research on the Application of Digital Image Information Resources in Colleges and Universities," Journal of JiaXing University 21, no. 1 (2009): $108-12$. 
52. Yoon, "Searching Images in Daily Life," 271; Ruiz and Chin, "Users' Image Seeking Behavior in a Multilingual Tag Environment," 37-44.

53. Goodrum and Spink, "Image Searching on the Excite Web Search Engine," 295-311.

54. Yoon, "Searching Images in Daily Life," 273.

55. Green, “Using Digital Images in Teaching and Learning Executive Summary,” 25.

56. Raya Fidel, "The Image Retrieval Rask: Implications for the Design and Evaluation of Image Databases," The New Review of Hypermedia and Multimedia 3, no. 1 (1997): 181-99.

57. Lori McCay-Peet and Elaine Toms, "Image Use within the Work Task Model: Images as Information and Illustration," Journal of the American Society for Information Science and Technology 60, no. 12 (2009): 2422

58. Lynne R. Conniss, A. Julie Ashford, and Margaret E. Graham, Information Seeking Behavior in Image Retrieval: Visor I Final Report: Library and Information Commission Research Report 95 (Newcastle upon Tyne: Institute for Image Data Research, 2000).

59. Chung and Yoon, "Image Needs in the Context of Image Use," 163.

60. Emma Angus and Mike Thelwall, "Motivations for Image Publishing and Tagging on Flickr," in Proceedings of the 14th International Conference on Electronic Publishing, eds. Turid Hedlund and Yasar Tonta (2010): 189-204.

61. Marcia J. Bates, "The Design of Browsing and Berry Picking Techniques for the Online Search Interface," Online Review 13, no. 5 (1989): 407-24.

62. Iain Campbell, "Interactive Evaluation of the Ostensive Model, Using a New Test Collection of Images with Multiple Relevance Assessments," Journal of Information Retrieval 2, no. 1 (2000): 89-114.

63. Matusiak, "Information Seeking Behavior in Digital Collections," 487.

64. John P. Eakins, Pam Briggs and Bryan Burford, "Image Retrieval Interfaces: A User's Perspective," Lecture Notes in Computer Science 3115 (2004): 635.

65. Beaudoin, "A Preliminary Investigation of Image Indexing," 1.

66. Erwin Panofsky, Studies in Iconology: Humanistic Themes in the Art of the Renaissance (New York: Harper \& Row, 1972).

67. Shatford, "Analyzing the Subject of a Picture," 39-62.

68. Carlo Colombo, Alberto Del Bimbo, and Pietro Pala, "Semantics in Visual Information Retrieval," IEEE Multimedia 6, no. 3 (1996): 38-53.

69. Michael G. Krause, "Intellectual Problems of Indexing Picture Collections," Audiovisual Librarian 14, no. 2 (1998): 73-81.

70. Howard Greisdorf and Brian O'Connor, "Modeling What Users See When They Look at Images: A Cognitive Viewpoint," Journal of Documentation 58, no. 1 (2002): 6-29.

71. Corinne Jörgensen, "Retrieving the Unretrievable in Electronic Imaging Systems: Emotions, Themes, and Stories," Human Vision and Electronic Imaging IV, Proceedings Volume 3644, (1999): 348-55; Stefanie Schmidt and Wolfgang G. Stock, "Collective Indexing of Emotions in Images: A Study in Emotional Information Retrieval," Journal of the American Society for Information Science and Technology 60, no. 5 (2009): 863-76; JungWon Yoon, “Utilizing Quantitative Users' Reactions to Represent Affective Meanings of an Image," Journal of the American Society for Information Science and Technology 61, no. 7 (2010): 1345-59.

72. Yoon, "Searching Images in Daily Life," 271.

73. Eakins, Briggs, and Burford, "Image Retrieval Interfaces," 628-37; Westman and Oittinen, “Image Retrieval by End-Users and Intermediaries in a Journalistic Work Context," 102-10.

74. Heting Chu and Yi Ao, How to Search Images over the Internet (Liaoning: Liaoning Science and Technology Press, 2007).

75. Pisciotta, Dooris, Frost, and Halm, "Penn State's Visual Image User Study," 33-58. 20.

76. James W. Marcum, “Rethinking Information Literacy," Library Quarterly 72, no. 1 (2002):

77. JungWon Yoon, "Searching for an Image Conveying Connotative Meanings: An Exploratory Cross-Cultural Study," Library and Information Science Research 30, no. 4 (2008): 312-18. 